\title{
OPTIMALISASI PRODUKSI MIX BED DENGAN PENAMBAHAN REAMANING DI PLTGU TAMBAK LOROK SEMARANG
}

\author{
David Ariyanto*, Handariansah \\ Indonesia Power Unit Pembangkitan Semarang \\ Jl. Ronggowarsito, Tanjung Mas, Semarang, Jawa Tengah 50174 \\ Email: * david.ariyanto@indonesiapower.co.id
}

\begin{abstract}
ABSTRAK
PLTGU Tambak Lorok Semarang merupakan pembangkit combined cycle yang memiliki 6 HRSG (Heat Recovery Steam And Generator) sebagai penghasil uap untuk operasional STG. Untuk itu diperlukan air demin sebagai air penambah dalam jumlah yang banyak guna menghasilkan uap. Raw water yang merupakan hasil dari desalination plant selanjutnya akan diolah ke dalam sistem mixbed. Indikator nilai kerja dari suatu kerja mix bed yaitu remaining. Remaining merupakan nilai total volume air demin yang dihasilkan oleh mix bed. Nilai desain remaining dari mix bed yaitu sebesar 5100, akan tetapi setelah mencapai remaining nol nilai konduktivity masih menunjukkan nilai $<0,8 \mu \mathrm{S} / \mathrm{cm}$. Untuk itu diperlukan penambahan remaining untuk semua mix bed, dengan penambahan tersebut akan menambah jumlah produksi dari mix bed sendiri dan tentunya akan mengurangi jumlah regenerasi. Program ini sudah dilaksanakan mulai bulan Oktober 2015 - Juni 2016, dan didapat nilai penambahan jumlah air demin sebesar $54.300 \mathrm{~m}^{3}$. Sedangkan pengurangan limbah B3 sebesar 378.642 liter.
\end{abstract}

Kata kunci : mix bed, demin water, limbah B3, prolong remaining

\section{PENDAHULUAN}

Demineralisasi merupakan suatu sistem yang bertujuan untuk mengikat ion-ion yang terdapat pada Raw Water sehingga hasil dari mix bed tersebut akan memiliki nilai konduktivity yang rendah $(<0,8 \mu \mathrm{S} / \mathrm{cm})$. Nilai konduktifitas tersebut merupakan syarat sebagai air pengisi HRSG (Heat Recovery Steam And Generator). Gambar reaktor mix bed ditunjukkan pada Gambar 1

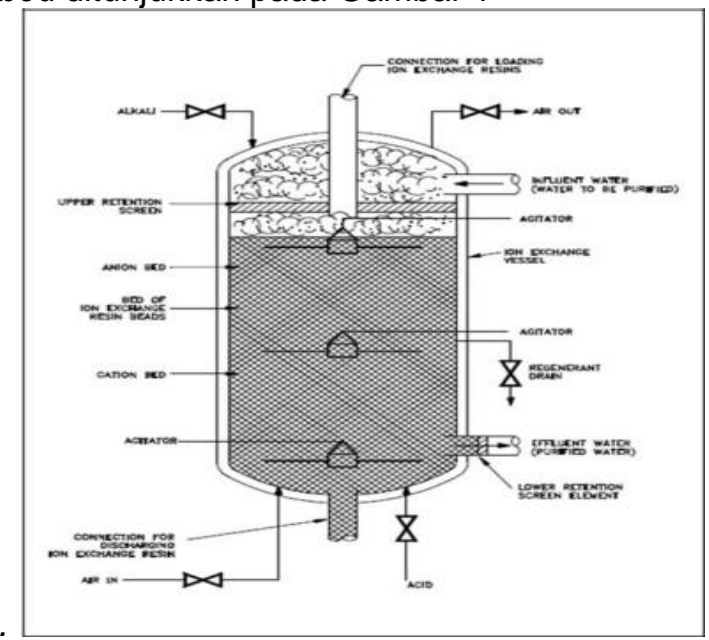

Gambar 1. Kolom Mix Bed

Secara umum kolom resin digunakan pada proses demineralisasi air. Kolom resin memiliki dua tipe yaitu Single Bed dan Mixed Bed Ion Exchange Resin. Single Bed berarti di dalam satu kolom hanya terdapat satu jenis resin yakni kation resin atau anion resin. Sedangkan kolom Mixed Bed berisi campuran resin kation dan anion. Proses utama pada mix bed ada 2, yaitu :

1. Operasional

2. Regenerasi

Resin kation berfungsi untuk megikat ionion positif yang terlarut pada raw water. Contoh reaksi ion antara resin dan senyawa $\mathrm{NaCl}$ sebagai berikut:

$\mathrm{R}-\mathrm{H}^{+}+\mathrm{Na}^{+} \rightarrow \mathrm{R}-\mathrm{Na}^{+}+\mathrm{Cl}^{-}$

Resin anion digunakan untuk mengikat ion-ion negatif yang terlarut pada raw water. Contoh reaksi ion antara resin dan senyawa $\mathrm{NaCl}$ sebagai berikut:

$\mathrm{R}-\mathrm{OH}^{-}+\mathrm{Cl}^{-} \rightarrow \mathrm{R}-\mathrm{Cl}^{-}+\mathrm{Na}^{+}$

Ketika resin mengalami kejenuhan maka akan dilakukan regenerasi. Ion negatif akan diregenasi dengan $\mathrm{NaOH}$ sedangkan untuk ion positif akan diregenerasi menggunakan $\mathrm{HCl}$. Reaksi regenerasi resin kation sebagai berikut:

$\mathrm{R}-\mathrm{Na}^{+}+\mathrm{HCl} \rightarrow \mathrm{R}-\mathrm{H}^{+}+\mathrm{Cl}^{-}$ 
Sedangkan untuk resin anion sebagai berikut:

$\mathrm{R}-\mathrm{Cl}^{-}+\mathrm{NaOH} \rightarrow \mathrm{R}^{-} \mathrm{OH}^{-}+\mathrm{Na}^{+}$

\section{METODOLOGI PENELITIAN}

Metode yang digunakan untuk menambah pasokan air demin dan mengurangi jumlah produksi limbah pada saat regenerasi adalah dengan menambah remaining produksi mix bed. Remaining merupakan daya kapasitas operasional dari suatu mix bed dan dinyatakan dalam satuan volume ton atau $\mathrm{m}^{3}$. Jika sebelum adanya inovasi ini bila remaining sudah mencapai nilai 0 dan konduktivity masih $<0,8 \mu \mathrm{S} / \mathrm{cm}$ langsung dilakukan regenerasi. Dengan inovasi ini dilakukan dengan cara menambah settingan awal atau design remaining (5100) jika mix bed yang sudah mencapai remaining nol (0) akan tetapi nilai konduktivity masih $\leq$ $0,8 \mu \mathrm{S} / \mathrm{cm}$. Dikarenakan nilai batas maksimal dari nilai konduktivity untuk air penambah hot well yang berupa air demin sebesar $0,8 \mu \mathrm{S} / \mathrm{cm}$. Penambahan nilai Remaining dilakukan secara automatis menggunakan software.

Penambahan remaining dilakukan secara bertahap, dikarenakan tidak ada acuan yang pasti untuk penambahan remaining pada setiap mix bed. Penambahan dilakukan sebesar 500 jika sudah mencapai nilai 0 (nol).

Adapun diagram alir untuk proses inovasi ini adalah sebagai berikut:

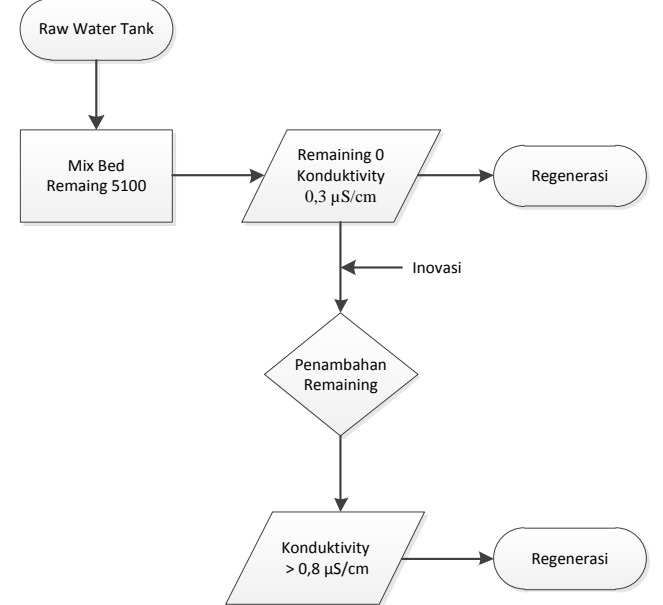

Gambar 2. Diagram alir inovasi

Inovasi ini juga selain memaksimalkan hasil untuk konservasi air, juga dapat mengurangi pemakaian bahan kimia regenerasi (pemakaian B3) dan pengurangan pemakaian power pada saat regenerasi (efisiensi energi).

\section{HASIL DAN PEMBAHASAN}

\section{Penambahan Air Demin}

Air demin disini digunakan sebagai air penambah HRSG yang mana jika operasional 6 unit HRSG (Heat Recovery Steam And Generator) maka pemakaian airnya akan besar pula (rata-rata $20 \mathrm{~m}^{3} / \mathrm{jam}$ ). Untuk itu diperlukan pasokan air demin yang handal dalam jumlah besar pula. Dengan adanya inovasi mix bed ini yang dari mulanya hanya 5100 ton setiap satu kali operasi, maka di dapat penambahan remaining rata-rata sekitar 2000 sampai resin Kation dan Anion jenuh (konduktivity $\geq 0,8 \mu \mathrm{S} / \mathrm{cm}$ ).

Tabel 1. Data Penambahan Remaining mix bed

\begin{tabular}{cccccc}
\hline \multirow{2}{*}{ No } & \multirow{2}{*}{ Bulan } & \multicolumn{3}{c}{ Mix Bed $\left(\mathrm{m}^{3}\right)$} & \multirow{2}{*}{ Total } \\
\cline { 3 - 5 } 1 & Okt. 2015 & 5.300 & & 3.000 & 8.300 \\
2 & Nov.2015 & 3.000 & 5.000 & & 8.000 \\
3 & Des.2015 & 1.000 & 1.000 & 500 & 2.500 \\
4 & Jan.2016 & 5.500 & & 500 & 6.000 \\
5 & Feb. 2016 & 1.000 & 4.500 & 1.000 & 6.500 \\
6 & Mar.2016 & 4.500 & 1.000 & 1.000 & 6.500 \\
7 & Apr. 2016 & 3.500 & 1.500 & 3.000 & 8.000 \\
8 & Mei 2016 & 3.000 & 2.500 & 1.000 & 6.500 \\
9 & Juni 2016 & 1.500 & & 500 & 2.000 \\
Jumlah Total & & & & 54.300 \\
\hline
\end{tabular}

Berdasarkan tabel diatas didapat penambahan total air demin sebesar 54.300 $\mathrm{m}^{3}$ yang berasal dari mix bed A, B dan C.

\section{Pengurangan Jumlah Bahan Kimia Regenerasi}

Penambahan nilai remaining pada mix bed tentunya akan memberikan beberapa keuntungan diantaranya mengurangi jumlah regenerasi setiap bulannya. Regenerasi ini berfungsi untuk mengaktifkan kembali resinresin yang sudah tidak bisa melakukan pertukaran ion.

Regenerasi melalui berbagai tahapan, yang mana sangat mempengaruhi hasi akhir dari mix bed. Tahapan itu diantaranya aplikasi bahan kimia, aliran, konsentrasi dan waktu juga sangat diperhatikan sehingga hasil akhirnya tidak ada sisa bahan kimia yang masih terperangkap yang melapisi resin.

Bahan kimia $\mathrm{NaOH}$ memakai satandar Spesifik Gravity sebesar 1,32 sedangkan untuk bahan kimia $\mathrm{HCl}$ memakai SG sebesar 1,19. Dengan total sekali regenerasi rata-rata untuk 


\section{Ariyanto, D., Handariansah}

Optimalisasi Produksi Mix Bed Dengan Penambahan Reamaning Di PLTGU Tambak Lorok Semarang

$\mathrm{NaOH}$ sebanyak 500 liter dan $\mathrm{HCl}$ sebesar 350 liter. Dengan adanya penambahan remaining maka didapat pengurangan regenerasi sebesar :

$$
\begin{aligned}
\mathrm{x} \text { regenerasi } & =\frac{\text { Total penambahan remaining }}{\text { desain awal }} \\
& =\frac{54300}{5100}=11 \mathrm{kali}
\end{aligned}
$$

Sehingga jumlah pengurangan bahan kimia sebagai berikut :

Tabel 2. Total pemakaian bahan kimia

\begin{tabular}{ccc}
\hline $\begin{array}{c}\text { Bahan } \\
\text { kimia }\end{array}$ & Volume (liter) & $\begin{array}{c}\text { Total } \\
\text { pengurangan } \\
\text { (liter) }\end{array}$ \\
\hline $\mathrm{HCl}$ & 350 & 3850 \\
$\mathrm{NaOH}$ & 500 & 5500 \\
\hline
\end{tabular}

Berdasarkan data diatas didapat nilai pengurangan pemakaian bahan kimia untuk regenerasi dari bulan Otober 2015-Juni 2016 sebesar :
a. $\mathrm{HCl}=3.850$ liter
b. $\mathrm{NaOH}=5.500$ liter

\section{Pengurangan Jumlah Limbah}

Proses regenerasi pada mix bed PLTGU Tambak Lorok melalui beberapa tahap dimana setiap tahap pastinya membutuhkan air dalam proses dan bahan kimia yang hasil akhirnya berupa limbah. Limbah tersebut akan dialirkan ke dalam WWTP (Waste Water Treatment Plant). Jika sebelum nya limbah yang dihasilkan hampir tiap minggu, maka dengan adanya inovasi ini limbah yang dihasilkan aka berkurang menjadi 2-3 minggu sekali sesuai dengan pelaksanaan regenerasi. Jumlah limbah regenerasi ditampilkan pada Tabel 3.

Berdasarkan Tabel 3, maka setiap kali pelaksanaan regenerasi dihasilkan limbah kurang lebih 34.422 liter. Jika total penghematan jumlah regenerasi sebanyak 11 kali dari periode Oktober 2015- Juni 2016 maka pengurangan total limbah sebanyak:

Total pengurangan $=34.422 \times 11=378.642$ liter. Dengan total pengurangan limbah sebanyak 378.642 liter maka akan mengurangi beban kerja dari WWTP (Waste Water Treatment Plant).

\section{Konservasi Air}

Pada proses regenerasi tentunya membutuhkan air dalam prosesnya, baik itu raw water dan demin water. Dengan adanya inovsi ini maka akan mengurangi jumlah pemakaian kedua air tersebut. Jumlah pemakaian air demin dan raw water ditunjukkan pada Tabel 4.

Konservasi air yang didapat priode Oktober 2015 - Juni 2016 sebesar :

Total konservasi air $=33.572 \times 11=378.642$ liter. Dari total sebesar 378.642 liter atau sebanding dengan 378,6 ton dapat digunakan sebagai air penambah HRSG (Heat Recovery Steam And Generator).

Tabel 3. Jumlah limbah regenerasi

\begin{tabular}{lccccc}
\hline \multirow{2}{*}{ Sequent } & Time (menit) & \multirow{2}{*}{ Flow (lpm) } & \multicolumn{4}{c}{ Pemakaian } \\
\cline { 5 - 6 } & A & BW & RW & Acid & Caustic \\
\hline Delay & 1,0 & & & & \\
Back Flush & 1,0 & 322 & & 322 & \\
Back Wash & 15,0 & 322 & & 4830 & \\
Bed Sattle & 4,0 & & & & \\
Compact Bed & 4,0 & 598 & & 2392 & \\
Estblish Water & 10,0 & 57 & 570 & & \\
Water Coustic & 10,0 & 61 & 610 & & \\
Establish concen & 3,0 & 57 & 171 & & \\
concentration & 3,0 & 61 & 183 & & \\
Acid Application & 32,0 & 57 & 1824 & & \\
Coustic Applicat & 62,0 & 61 & 3782 & & \\
Caustic Slow Rin & 17,0 & 61 & 1037 & & \\
Caustic Fast Rins & 23,0 & 378 & & 8694 & \\
Drain down & 12,0 & & & & \\
Bed Loosen & 0,4 & 322 & & & \\
Air Mix & 5,0 & & & & \\
Bed Lock & 1,0 & & & & \\
Slow Fill & 11,0 & 61 & 666 & & \\
& & & & &
\end{tabular}




\begin{tabular}{|c|c|c|c|c|c|c|}
\hline \multirow{2}{*}{ Sequent } & \multirow{2}{*}{ Time (menit) } & \multirow{2}{*}{ Flow (Ipm) } & \multicolumn{4}{|c|}{ Pemakaian } \\
\hline & & & DW & RW & Acid & Caustic \\
\hline & A & B & $C=A \times B$ & $D=A \times B$ & & \\
\hline Fast Fill & 7,0 & 322 & & 2254 & & \\
\hline Fina IFast Rinse & 11,0 & 567 & & 6237 & & \\
\hline Rinse Recycle & 33,0 & & & & & \\
\hline Service & 10,0 & & & & & \\
\hline Jumlah & 4,6 & & 8,843 & 25 & 350 & 500 \\
\hline Total limbah satu kali & genreasi (liter) & & & 422 & & \\
\hline
\end{tabular}

Tabel 4. Jumlah pemakaian air demin dan raw water

\begin{tabular}{|c|c|c|c|c|}
\hline \multirow{2}{*}{ Sequent } & \multirow{2}{*}{ Time } & \multirow{2}{*}{ Flow (Ipm) } & \multicolumn{2}{|c|}{ Pemakaian } \\
\hline & & & Demin W & Raw W \\
\hline & A & $\mathrm{B}$ & $\mathrm{C}=\mathrm{A} \times \mathrm{B}$ & $D=A \times B$ \\
\hline Back Flush & 1 & 322 & & 322 \\
\hline Back Wash & 15 & 322 & & 4.830 \\
\hline Compact Bed & 4 & 598 & & 2.392 \\
\hline Establish Water acid & 10 & 57 & 570 & \\
\hline Water Coustic & 10 & 61 & 610 & \\
\hline Establish concentration A & 3 & 57 & 171 & \\
\hline Concentration C & 3 & 61 & 183 & \\
\hline Acid Application & 32 & 57 & 1.824 & \\
\hline Coustic Application & 62 & 61 & 3.782 & \\
\hline Caustic Slow Rinse & 17 & 61 & 1.037 & \\
\hline Caustic Fast Rinse & 23 & 378 & & 8.694 \\
\hline Bed Loosen & 0 & 322 & & \\
\hline Slow Fill & 11 & 61 & 666 & \\
\hline Fast Fill & 7 & 322 & & 2.254 \\
\hline Final Fast Rinse & 11 & 567 & & 6.237 \\
\hline Jumlah & 3 & & 8.843 & 24.729 \\
\hline Total pemakaian air & & & & \\
\hline
\end{tabular}

\section{KESIMPULAN}

1. Penambahan remaining atau prolong dapat menambah pasokan air demin.

2. Penambahan remaining juga dapat mengurangi jumlah pemakaian bahan kimia regenrasi $(\mathrm{HCl}$ dan $\mathrm{NaOH})$, RAW water dan Demin Water untuk proses regenerasi.

3. Penambahan remaining juga dapat mengurangi jumlah limbah dari proses regenerasi.

4. Total penambahan air demin sebesar $53.800 \mathrm{~m}^{3}$ dan pengurangan limbah cair yang sebanyak 378.642 liter selama periode Oktober 2015 - Juni 2016.

5. Total konservasi yang dihasilkan sebanyak 378.642 liter.

\section{DAFTAR PUSTAKA}

Anonim 2012. Hybrid Control Designer, HC900-C50, Mix bed Plant PLTGU Tambak Lorok Semarang, Semarang: Unit Bisnis Pembangkitan Semarang.

Black \& Veatch Sumitomo Corporation. 1995. Tambak Lorok Combined Cycle Power Plant, Off-Site training Program For PLN Volume 1,. Semarang: Unit Bisnis Pembangkitan Semarang

Hungerford \& Terry, Inc, 1995. Cycle Make-Up Water Treatment System, Tambak Lorok Combined Cycle Plant Perusahaan. Semarang: Unit Bisnis Pembangkitan Semarang.

Tri Mudiyat, 2007. Internal Treatment, Unit Bisnis Pembangkitan Semarang. Semarang: Unit Bisnis Pembangkitan Semarang. 